\title{
A New Selective Synthesis of Dithiaboroles as a Viable Pathway to Functionalized Benzenedithiolenes and their Complexes
}

Simon H. Schlindwein, ${ }^{\mathrm{a}}$ Katharina Bader, ${ }^{\mathrm{b}}$ Carlo Sibold, ${ }^{\mathrm{a}}$ Wolfgang Frey, ${ }^{\mathrm{c}}$ Petr Neugebauer, ${ }^{\mathrm{b}}$ Milan Orlita, ${ }^{d}$ Joris van Slageren, ${ }^{b}$ Dietrich Gudat*a

${ }^{a}$ Institute of Inorganic Chemistry, University of Stuttgart, Germany

${ }^{b}$ Institute of Physical Chemistry, University of Stuttgart

c Institute of Organic Chemistry, University of Stuttgart, Germany

d Laboratoire National des Champs Magnétiques Intenses, Grenoble, France 


\section{Supporting Information}

Contents

Table S1 (crystallographic data for 1, 2, 4 and 5)

Figure S1 (molecular structures of 1, 2, 4 and 5)

Table S2 (crystallographic data for 7b, 7c, 7d' and 9d)

Table S3 (crystallographic data for $\left[\mathrm{Et}_{4} \mathrm{~N}\right] \mathbf{1 0},\left[\mathrm{Et}_{3} \mathrm{NH}\right] \mathbf{1 1}$, and 12)

Figures S2 \& S3 (intermolecular interactions in crystalline dithioboroles)

Figure S4 (plot of $\delta^{31} \mathrm{P}$ of 10 vs. $1 / \mathrm{T}$ )

Figure S5 (Solution UV-Vis spectra of $\left[\mathrm{NEt}_{4}\right] \mathbf{1 0},\left[\mathrm{NEt}_{3} \mathrm{H}\right] \mathbf{1 1}$ and Dithiol 4)

Figure S6 (Solid-state UV-Vis spectrum of $\left.\left[\mathrm{NEt}_{4}\right] 10\right)$

Figures $\mathrm{S} 7 \& \mathrm{~S} 8\left(\mathrm{VT}^{1} \mathrm{H}\right.$ - and ${ }^{31} \mathrm{P}-\mathrm{NMR}$-spectra of $\left.\left[\mathrm{NEt}_{4}\right] 10\right)$

Figures S9 \& S10 ( ${ }^{1} \mathrm{H}$ - and ${ }^{11} \mathrm{~B}-\mathrm{NMR}$-spectroscopic monitoring of the deprotection of $\left.6 \mathrm{a}\right)$

Figure S11 (Plot of Magnetization vs. applied magnetic field for $\left[\mathrm{HNEt}_{3}\right] \mathbf{1 1}$ )

Figure S12 (Plot of the susceptibility temperature product vs. temperature for $\left[\mathrm{HNEt}_{3}\right] \mathbf{1 1}$ )

Figure S13 (X-band EPR spectra of $\left[\mathrm{HNEt}_{3}\right] \mathbf{1 1}$ at $5 \mathrm{~K}$ )

Figure S14 (X-band EPR spectra of $\left[\mathrm{HNEt}_{3}\right] \mathbf{1 1}$ at various temperatures)

Figure S15 (HFEPR spectra of $\left[\mathrm{HNEt}_{3}\right] \mathbf{1 1}$ at various temperatures)

Figure S16 (Plot of Magnetization vs. applied magnetic field for $\left[\mathrm{NEt}_{4}\right] \mathbf{1 0}$ )

Figure S17 (Difference between experimental data and simulation of magnetization as a function of applied magnetic field of $\left.\left[\mathrm{NEt}_{4}\right] \mathbf{1 0}\right)$

Figure S18 (Far infrared spectra of $\left[\mathrm{NEt}_{4}\right] \mathbf{1 0}$ diluted in eicosan)

Figure S19 (Temperature dependence of $\chi^{\top}$ (open squares) of $\left.\left[\mathrm{NEt}_{4}\right] 10\right)$ 
Table S1. X-ray Details for 1, 2, 4, and 5.

\begin{tabular}{|c|c|c|c|c|}
\hline & 1 & $2^{a}$ & 4 & 5 \\
\hline empirical formula & $\mathrm{C}_{19} \mathrm{H}_{15} \mathrm{Cl}_{2} \mathrm{OP}$ & $\mathrm{C}_{25} \mathrm{H}_{29} \mathrm{~S}_{2} \mathrm{OP}$ & $\mathrm{C}_{19} \mathrm{H}_{17} \mathrm{OPS}_{2}$ & $\mathrm{C}_{19} \mathrm{H}_{17} \mathrm{PS}_{2}$ \\
\hline formula weight $\left(\mathrm{g} \cdot \mathrm{mol}^{-1}\right)$ & 361.18 & 440.57 & 356.42 & 340.42 \\
\hline$T(\mathrm{~K})$ & $110(2)$ & $100(2)$ & $100(2)$ & $100(2)$ \\
\hline crystal size (mm) & $0.25 \times 0.11 \times 0.08$ & $0.16 \times 0.07 \times 0.05$ & $0.58 \times 0.39 \times 0.23$ & $0.49 \times 0.22 \times 0.17$ \\
\hline space group & $\mathrm{P} 22_{1} / \mathrm{n}$ & $\mathrm{P} 22_{1} / \mathrm{n}$ & $\mathrm{Pbca}$ & $\mathrm{P} 2{ }_{1} / \mathrm{c}$ \\
\hline$a(\AA)$ & $5.4262(5)$ & $6.3515(12)$ & $11.4978(5)$ & $5.4293(4)$ \\
\hline$b$ & $9.5083(9)$ & $20.724(3)$ & $13.3495(6)$ & $17.2807(10)$ \\
\hline c & $32.704(4)$ & $17.811(3)$ & $22.0594(11)$ & $17.9861(11)$ \\
\hline$\beta$ & $90.447(4)$ & $98.948(9)$ & 90 & $95.141(3)$ \\
\hline$V \AA^{3}$ & $1687.3(3)$ & $2315.9(7)$ & $3385.9(3)$ & $1680.71(19)$ \\
\hline$Z$ & 4 & 4 & 8 & 4 \\
\hline$D_{\mathrm{c}}\left(\mathrm{mg} \cdot \mathrm{m}^{-3}\right)$ & 1.422 & 1.264 & 1.398 & 1.345 \\
\hline$\mu\left(\mathrm{mm}^{-1}\right)$ & 0.480 & 0.313 & 0.410 & 0.405 \\
\hline$F(000)$ & 744 & 936 & 1488 & 712 \\
\hline$\Theta$ range (deg) & 2.31 to 26.36 & 1.52 to 25.06 & 1.85 to 30.48 & 1.64 to 28.34 \\
\hline reflections collected & 12694 & 18735 & 33966 & 28887 \\
\hline unique reflections & 3448 & 4146 & 5140 & 4173 \\
\hline$R_{\text {int }}$ & 0.0721 & 0.0999 & 0.0516 & 0.0365 \\
\hline max./min transmission & $07444 / 0.6973$ & $0.7452 / 0.6256$ & $0.7461 / 0.6599$ & $0.7457 / 0.7077$ \\
\hline data/restraints/parameters & 3448 / 0 / 245 & $4146 / 0 / 267$ & $5140 / 0 / 216$ & $4173 / 0 / 207$ \\
\hline G.o.F. on $F^{2}$ & 1.011 & 1.094 & 1.121 & 1.041 \\
\hline$R 1[\mathrm{I}>2 \sigma(\mathrm{I})]$ & 0.0459 & 0.0945 & 0.0458 & 0.0321 \\
\hline $\mathrm{w} R 2\left(F^{2}\right)$ & 0.0927 & 0.2801 & 0.1085 & 0.0452 \\
\hline large diff. peak/hole $\left(e \AA^{-3}\right)$ & 0.376 and -0.3796 & 1.227 and -0.539 & 0.615 and -0.707 & 0.511 and -0.229 \\
\hline
\end{tabular}

${ }^{a}$ Rotational twin with two domains
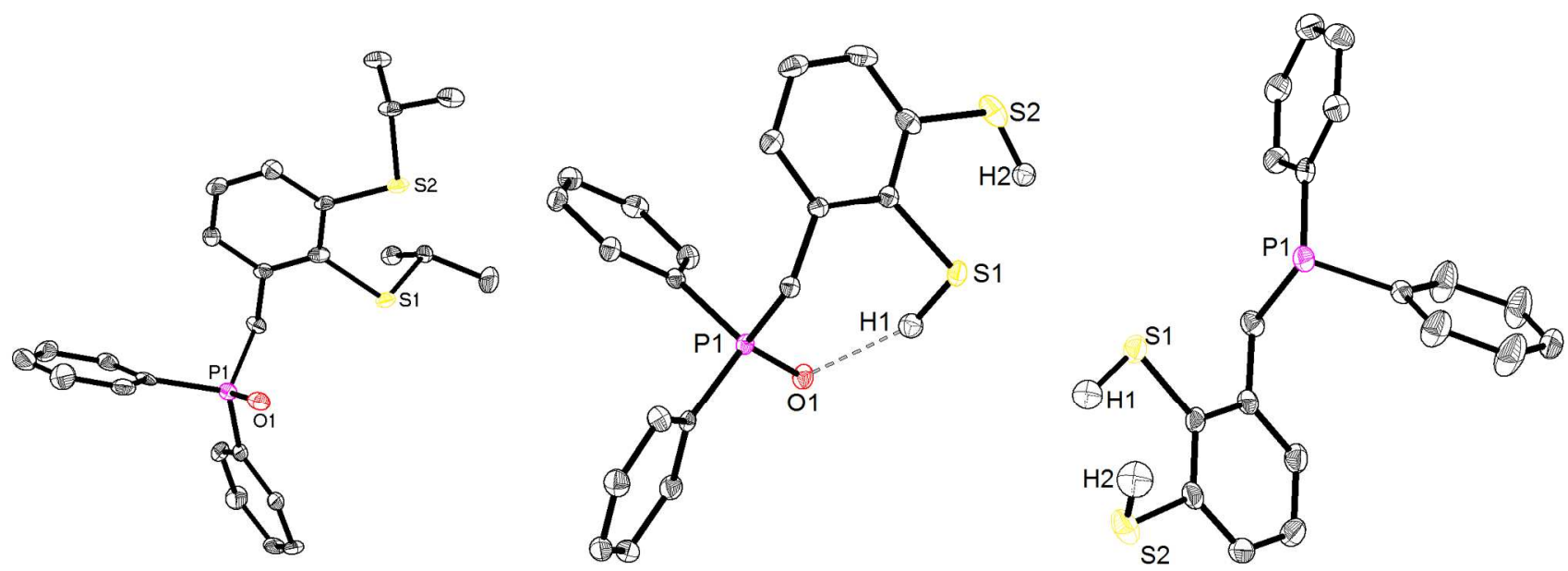

Figure S1. Molecular structures of 2, 4 and $\mathbf{5}$ (from left to right). Thermal ellipsoids are drawn at 50\% probability level. C-bound hydrogen atoms were omitted for clarity. 
Table S2. X-ray Details for 7b, 7c, 7d', and 9d.

\begin{tabular}{|c|c|c|c|c|}
\hline & $7 \mathbf{b}$ & 7c & $7 d^{\prime}$ & $9 d$ \\
\hline empirical formula & $\mathrm{C}_{9} \mathrm{H}_{10} \mathrm{~B}_{2} \mathrm{Br}_{4} \mathrm{~S}_{3}$ & $\mathrm{C}_{6} \mathrm{H}_{2} \mathrm{~B}_{2} \mathrm{Br}_{2} \mathrm{~S}_{4}$ & $\mathrm{C}_{12} \mathrm{H}_{16} \mathrm{~B}_{3} \mathrm{Br}_{7} \mathrm{~S}_{4}$ & $\mathrm{C}_{9} \mathrm{H}_{9} \mathrm{~B}_{2} \mathrm{Br}_{3} \mathrm{~S}_{4}$ \\
\hline formula weight $\left(\mathrm{g} \cdot \mathrm{mol}^{-1}\right)$ & 555.59 & 383.76 & 880.29 & 506.75 \\
\hline$T(\mathrm{~K})$ & $100(2)$ & $100(2)$ & $100(2)$ & $150(2)$ \\
\hline crystal size (mm) & $0.25 \times 0.25 \times 0.20$ & $0.23 \times 0.10 \times 0.06$ & $0.34 \times 0.18 \times 0.16$ & \\
\hline space group & $\mathrm{C} 2 / \mathrm{c}$ & $\mathrm{P} 2{ }_{1} / \mathrm{c}$ & $P-1$ & $\mathrm{P} 22_{1} / \mathrm{C}$ \\
\hline$a(\AA ̊)$ & $21.395(4)$ & $3.9678(6)$ & $8.1081(5)$ & $7.6486(6)$ \\
\hline b $(\AA ̊)$ & $10.626(2)$ & $12.692(2)$ & $10.9683(6)$ & $14.1797(9)$ \\
\hline c $(\AA)$ & $15.892(3)$ & $11.0080(2)$ & $15.0822(8)$ & $15.0546(2)$ \\
\hline$\alpha\left(^{\circ}\right)$ & 90 & 90 & $97.811(3)$ & 90 \\
\hline$\beta\left({ }^{\circ}\right)$ & $112.32(3)$ & $92.342(5)$ & $103.292(3)$ & $96.171(2)$ \\
\hline$\nu\left({ }^{\circ}\right)$ & 90 & 90 & 101.172(3) & 90 \\
\hline$V \AA^{3}$ & $3342.2(12)$ & $553.88(15)$ & $1257.54(12)$ & $1623.3(2)$ \\
\hline Z & 8 & 2 & 2 & 4 \\
\hline$D_{c}\left(\mathrm{mg} \cdot \mathrm{m}^{-3}\right)$ & 2.208 & 2.301 & 2.325 & 2.074 \\
\hline$\mu\left(\mathrm{mm}^{-1}\right)$ & 9.986 & 8.020 & 11.498 & 7.947 \\
\hline$F(000)$ & 2096 & 364 & 824 & 968 \\
\hline$\Theta$ range (deg) & 2.06 to 26.38 & 2.45 to 25.00 & 1.93 to 28.42 & 1.98 to 28.28 \\
\hline reflections collected & 13085 & 3988 & 22472 & 15253 \\
\hline unique reflections & 3412 & 963 & 6281 & 3995 \\
\hline$R_{\text {int }}$ & 0.0505 & 0.0291 & 0.0587 & 0.0402 \\
\hline max./min transmission & $0.1829 / 0.0959$ & $0.7392 / 0.405$ & $0.3706 / 0.0957$ & 0.2596 and 0.1095 \\
\hline data/restraints/parameters & $3412 / 0 / 165$ & $963 / 0 / 64$ & $6281 / 0 / 239$ & $3995 / 0 / 163$ \\
\hline G.o.F. on $F^{2}$ & 1.051 & 1.169 & 0.966 & 1.010 \\
\hline$R 1[I>2 \sigma(I)]$ & 0.0415 & 0.0456 & 0.0349 & 0.0249 \\
\hline $\mathrm{w} R 2\left(F^{2}\right)$ & 0.0797 & 0.1152 & 0.0514 & 0.0443 \\
\hline large diff. peak/hole $\left(e \AA^{-3}\right.$ ) & 1.356 and -1.087 & 2.331 and $-0.729^{a}$ & 0.600 and -0.686 & 0.513 and -0.559 \\
\hline
\end{tabular}

${ }^{a}$ Solvate containing two DMF molecules. 
Table S3. X-ray Details for $\left[\mathrm{Et}_{4} \mathrm{~N}\right] 10,\left[\mathrm{HNEt}_{3}\right] 11$, and 12.

\begin{tabular}{|c|c|c|c|}
\hline & {$\left[\mathrm{Et}_{4} \mathrm{~N}\right] \mathbf{1 0}$} & {$\left[\mathrm{Et}_{3} \mathrm{NH}\right] \mathbf{1 1}$} & $12^{a}$ \\
\hline empirical formula & $\mathrm{C}_{46} \mathrm{H}_{50} \mathrm{CoNO}_{2} \mathrm{P}_{2} \mathrm{~S}_{4}$ & $\mathrm{C}_{44} \mathrm{H}_{46} \mathrm{NNiO}_{2} \mathrm{P}_{2} \mathrm{~S}_{4}$ & $\mathrm{C}_{44} \mathrm{H}_{46} \mathrm{~N}_{2} \mathrm{O}_{2} \mathrm{P}_{2} \mathrm{PdS}_{4}$ \\
\hline formula weight $\left(\mathrm{g} \cdot \mathrm{mol}^{-1}\right)$ & 897.98 & 869.71 & 931.41 \\
\hline$T(\mathrm{~K})$ & $100(2)$ & $100(2)$ & $100(2)$ \\
\hline crystal size (mm) & $0.53 \times 0.23 \times 0.10$ & $0.12 \times 0.08 \times 0.07$ & $0.24 \times 0.08 \times 0.03$ \\
\hline space group & $\mathrm{C} 2 / \mathrm{c}$ & $P-1$ & $\mathrm{P} 21 / \mathrm{n}$ \\
\hline$a(\AA)$ & $24.417(3)$ & $12.690(2)$ & $14.2038(10)$ \\
\hline $\mathrm{b}(\AA \AA)$ & $11.1257(14)$ & $13.161(3)$ & $8.1279(5)$ \\
\hline$c(\AA)$ & $16.921(2)$ & $13.853(3)$ & $19.2114(13)$ \\
\hline$\alpha\left({ }^{\circ}\right)$ & 90 & $109.413(6)$ & 90 \\
\hline$\beta\left(\left(^{\circ}\right)\right.$ & $111.050(3)$ & $99.263(6)$ & $106.460(5)$ \\
\hline$\gamma\left({ }^{\circ}\right)$ & 90 & $92.666(5)$ & 90 \\
\hline$V \AA^{3}$ & $4289.9(9)$ & $2141.1(7)$ & $2127.0(2)$ \\
\hline Z & 4 & 2 & 2 \\
\hline$D_{\mathrm{c}}\left(\mathrm{mg} \cdot \mathrm{m}^{-3}\right)$ & 1.390 & 1.349 & 1.454 \\
\hline$\mu\left(\mathrm{mm}^{-1}\right)$ & 0.709 & 0.760 & 6.373 \\
\hline$F(000)$ & 1880 & 910 & 960 \\
\hline$\Theta$ range (deg) & 2.04 to 26.52 & 1.59 to 25.05 & 3.45 to 66.28 \\
\hline reflections collected & 14707 & 29254 & 14085 \\
\hline unique reflections & 4295 & 7506 & 3584 \\
\hline$R_{\text {int }}$ & 0.0341 & 0.1302 & 0.0638 \\
\hline max./min transmission & 0.7454 / 0.6442 & $0.7307 / 0.6747$ & $0.8787 / 0.3440$ \\
\hline data/restraints/parameters & $4295 / 0 / 292$ & $7506 / 0 / 494$ & 3584 / 0 / 254 \\
\hline G.o.F. on $F^{2}$ & 1.045 & 0.976 & 1.037 \\
\hline$R 1[I>2 \sigma(I)]$ & 0.041 & 0.0627 & 0.0467 \\
\hline $\mathrm{W} R 2\left(F^{2}\right)$ & 0.0985 & 0.1367 & 0.1305 \\
\hline large diff. peak/hole $\left(\mathrm{e} \AA^{-3}\right)$ & 0.523 and -0.405 & 0.823 and -0.618 & 1.777 and 0.620 \\
\hline
\end{tabular}

${ }^{\mathrm{a}}$ Solvate containing two DMF molecules.
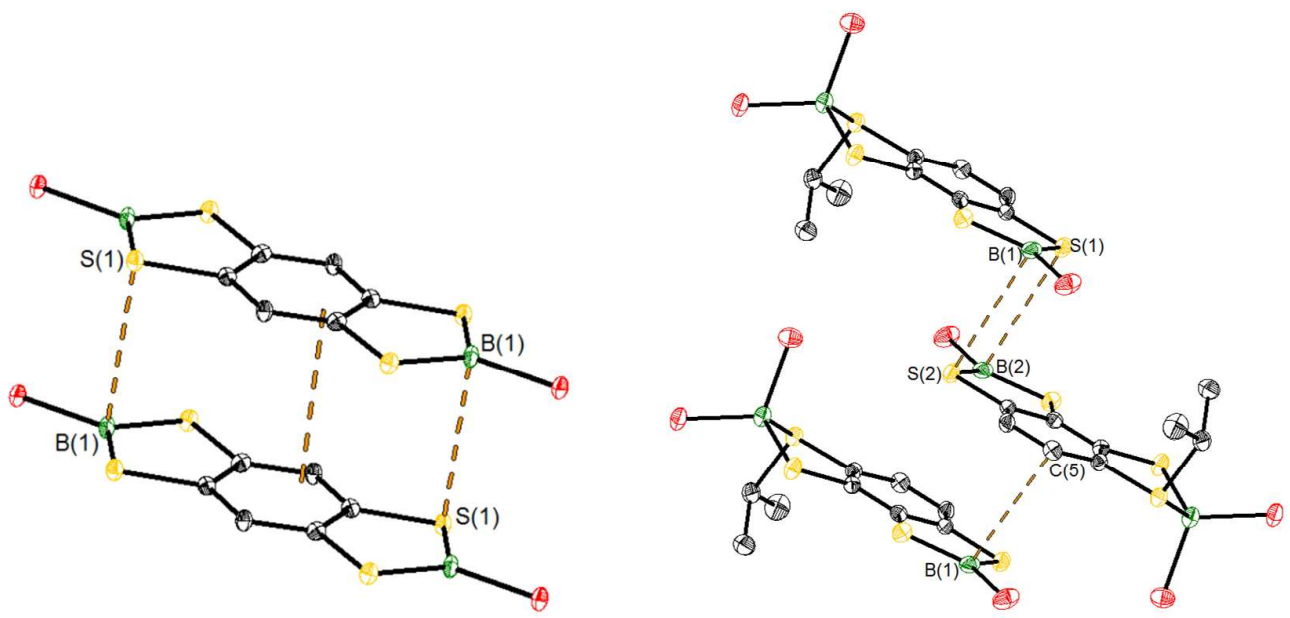

Figure S2. Depiction of $\pi$-stacking interactions in crystalline 7c and 9d. Dashed lines denote intermolecular contacts between molecules in different layers that are shorter than the sum of the van-der-Waals-radii. Contact distances in 7c B(1)-S(1) $3.547 \AA$ and in 9d B(1)-S(2) $3.644 \AA, B(2)-S(1) 3.644 \AA, C(5)-B(1) 3.504 \AA$. 

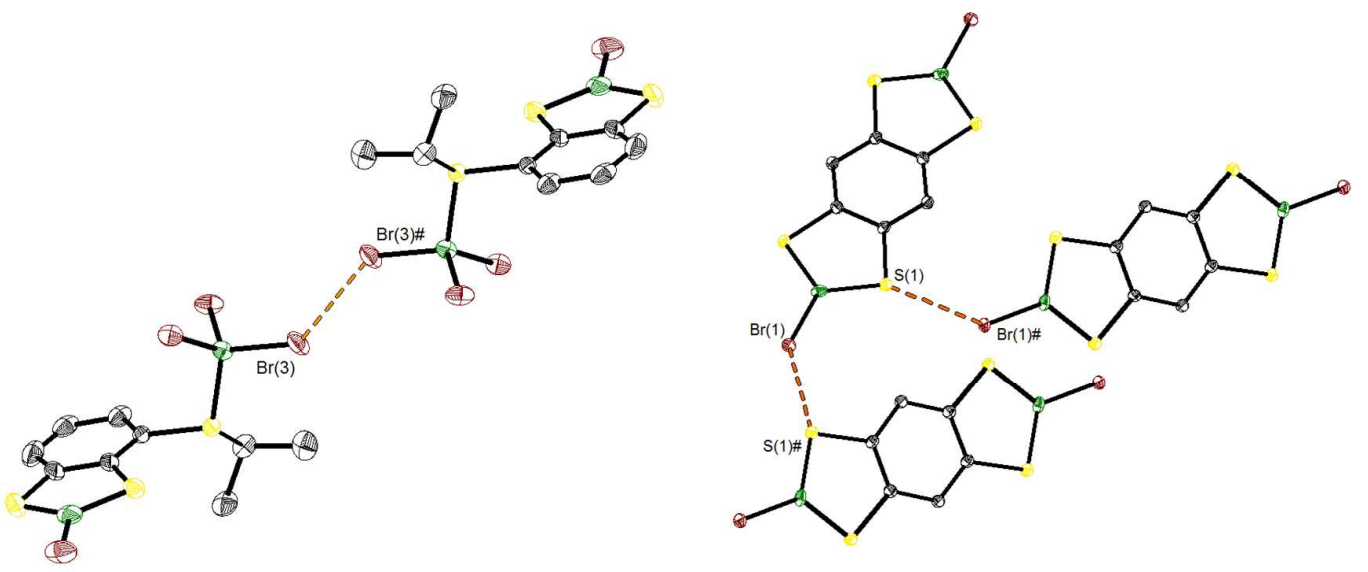

Figure S3. Depiction of intermolecular $\mathrm{S}-\mathrm{Br}$ and $\mathrm{Br}-\mathrm{Br}$ interactions in crystalline $\mathbf{7 b}$ and $\mathbf{7 c}$. Dashed lines denote contacts between atoms in different molecules that are shorter than the sum of the van-der-Waals-radii. Contact distances in 7b $\mathrm{Br}(3)-\mathrm{Br}(3) \# 3.588 \AA$ and in 7c Br(1)\#-S(1) $3.649 \AA, \operatorname{Br}(1)-\mathrm{S}(1) \# 3.649 \AA$.

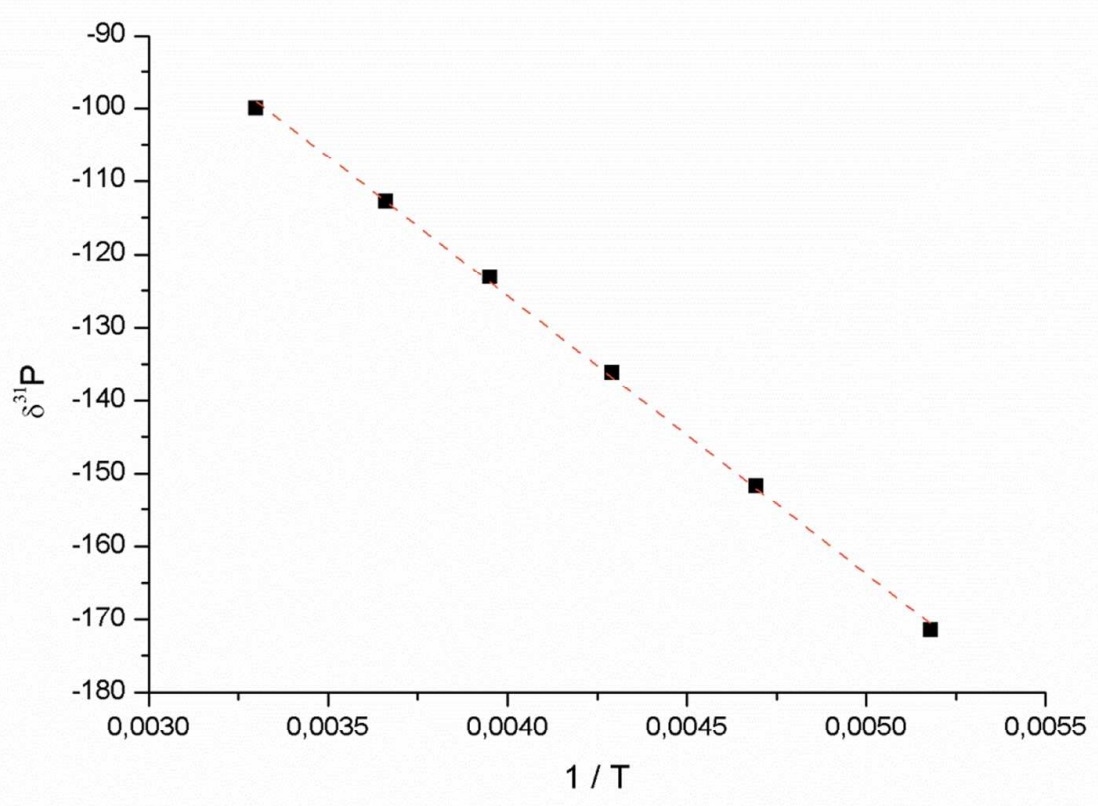

Figure S4. Plot of average $\delta^{31} \mathrm{P}$ of $\left[\mathrm{NEt}_{4}\right] 10 \mathrm{vs.} 1 / \mathrm{T}$ (squares) with linear regression fit (dashed line). 


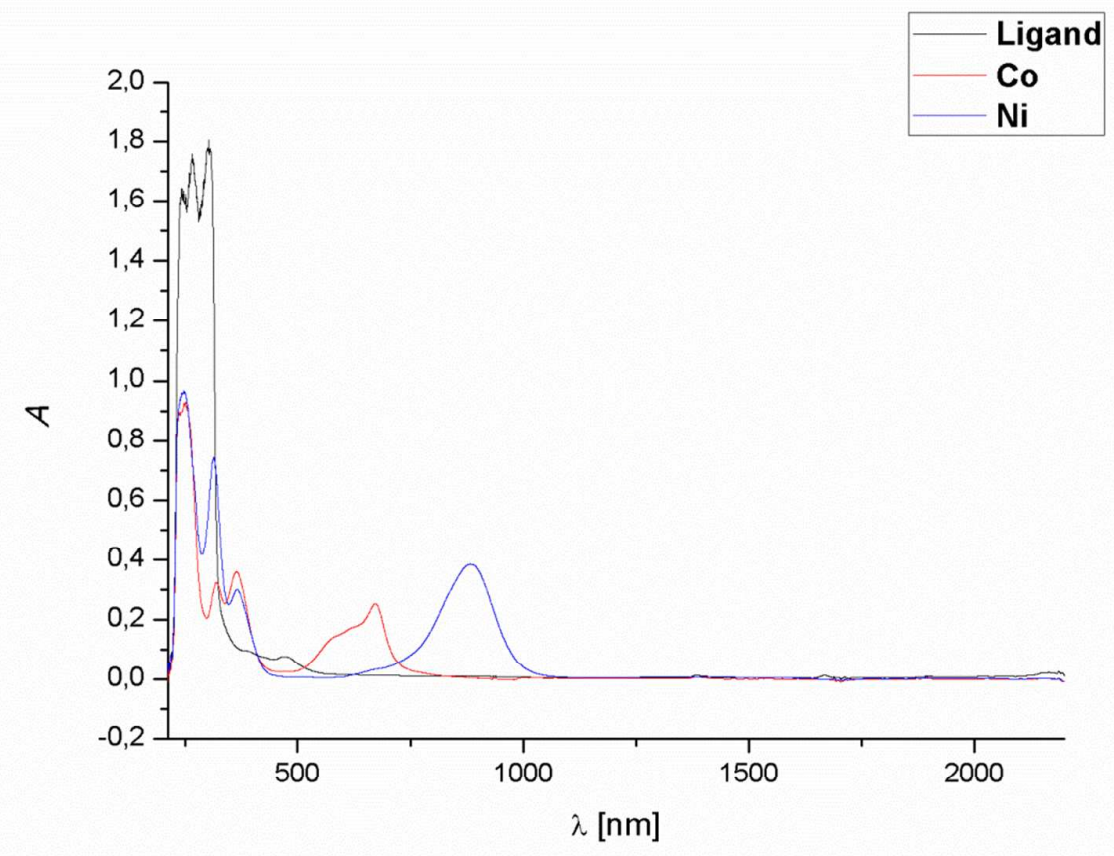

Figure S5. UV-Vis spectra of $\left[\mathrm{NEt}_{4}\right] \mathbf{1 0},\left[\mathrm{NEt}_{3} \mathrm{H}\right] \mathbf{1 1}$ and Dithiol 4.

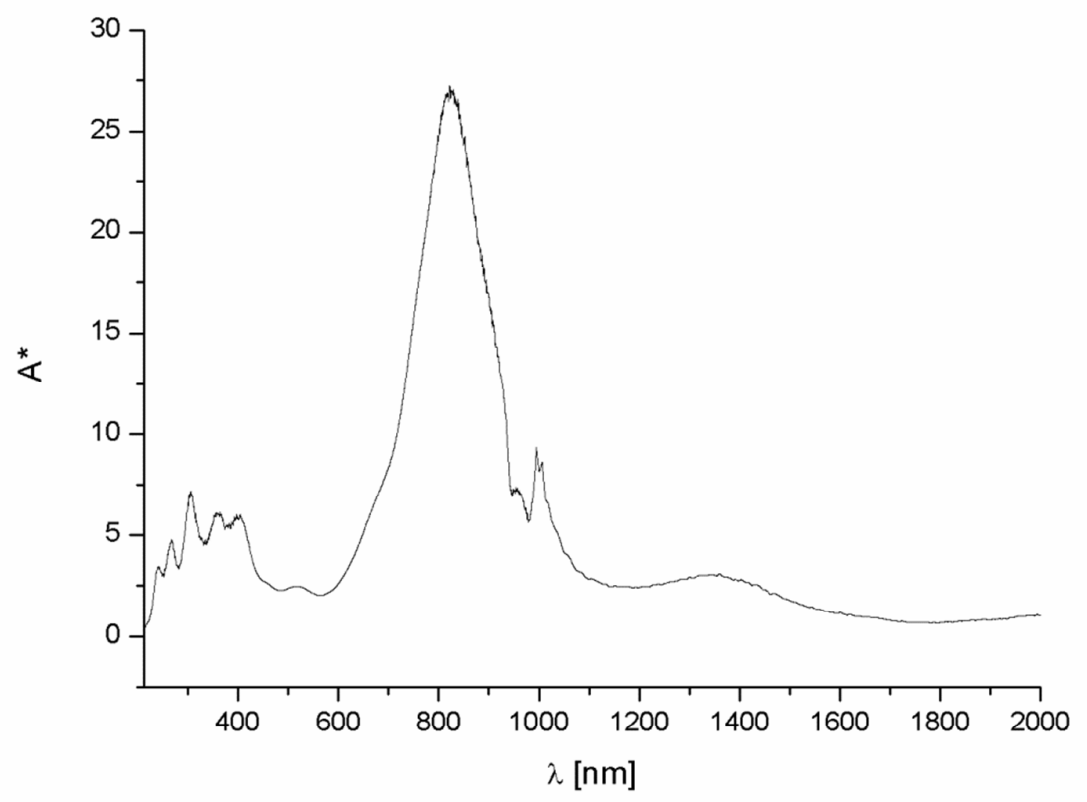

Figure S6. Diffuse reflexion solid-state UV-Vis spectrum of $\left[\mathrm{NEt}_{3} \mathrm{H}\right] \mathbf{1 1}$. The absorbance was derived from the spectral transmission by a Kubelka-Munk-function. The feature around $1350 \mathrm{~nm}$ is an artefact. 


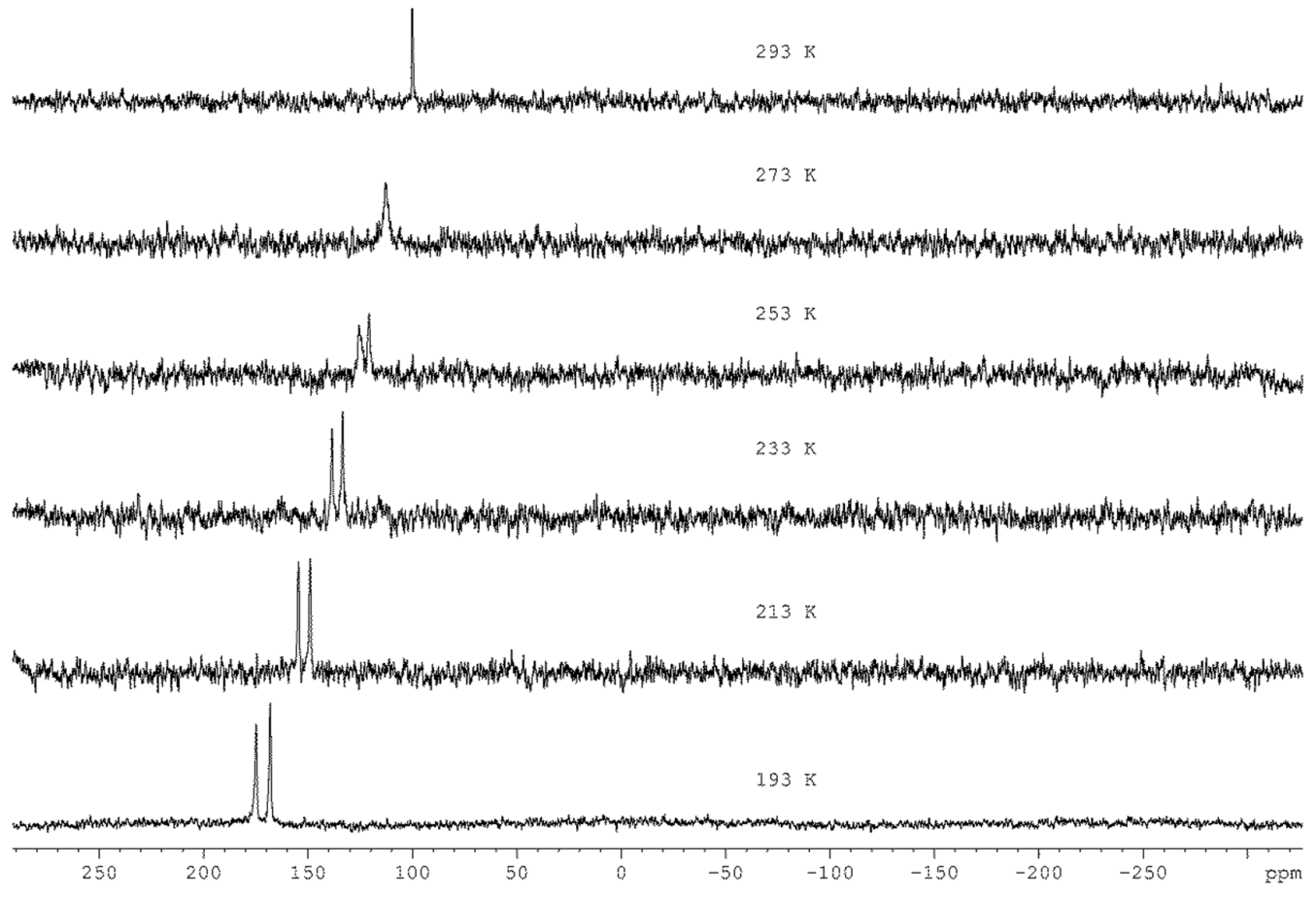

Figure S7. ${ }^{31} \mathrm{P}$ NMR spectra of $\left[\mathrm{NEt}_{4}\right] 10$ recorded between $-80^{\circ} \mathrm{C}(193 \mathrm{~K})$ and $20^{\circ} \mathrm{C}(293 \mathrm{~K})$.

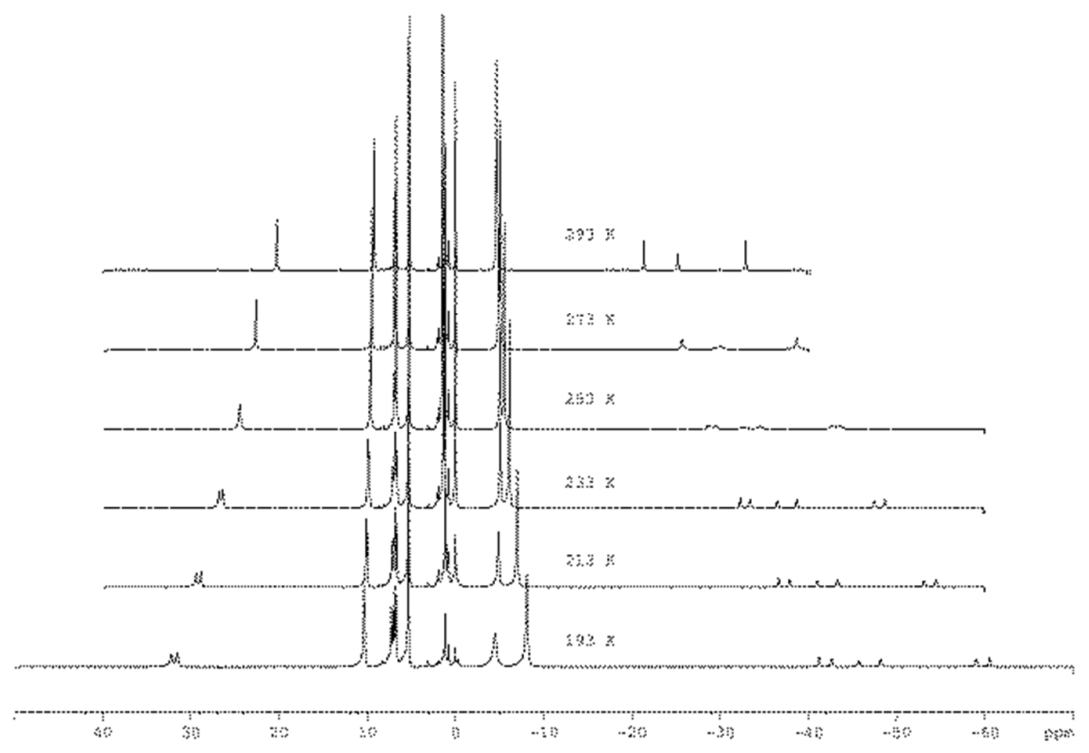

Figure S8. ${ }^{1} \mathrm{H}-\mathrm{NMR}$ spectra of $\left[\mathrm{Et}_{4} \mathrm{~N}\right] 10$ recorded between $-80{ }^{\circ} \mathrm{C}(193 \mathrm{~K})$ and $20^{\circ} \mathrm{C}(293 \mathrm{~K})$. Decoalescence phenomena induces a splitting of the signals of the $\mathrm{H}$-atoms in the $\mathrm{CH}_{2}$ groups (between $35-20 \mathrm{ppm}$ ) and dithiolene units $(-20--60$ $\mathrm{ppm}$ ) into two nearly equally intense sets at lower temperatures. 


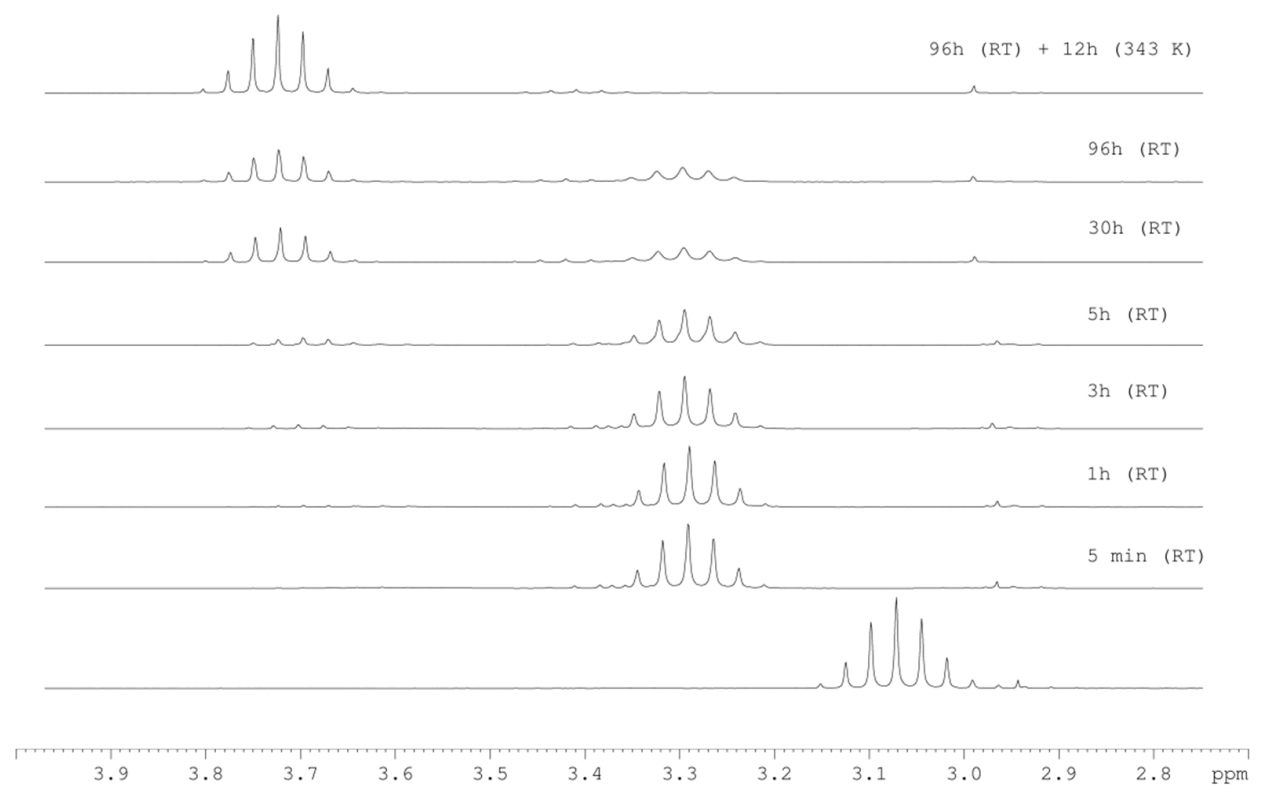

Figure S9. ${ }^{1} \mathrm{H}$ NMR spectroscopic monitoring of the reaction of 1,2-bis(isopropylthio)benzene with 1 eq. of $\mathrm{BBr}_{3}$. The bottom spectrum was acquired before addition of $\mathrm{BBr}_{3}$.

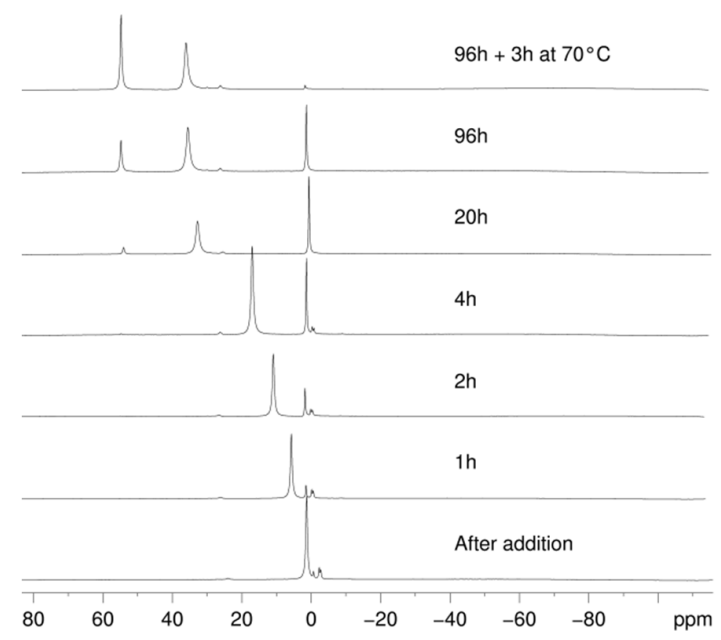

Figure S10. ${ }^{11} \mathrm{~B}$ NMR spectroscopic monitoring of the reaction of 1,2-bis(isopropylthio)benzene with 2 eq. of $\mathrm{BBr}_{3}$. 


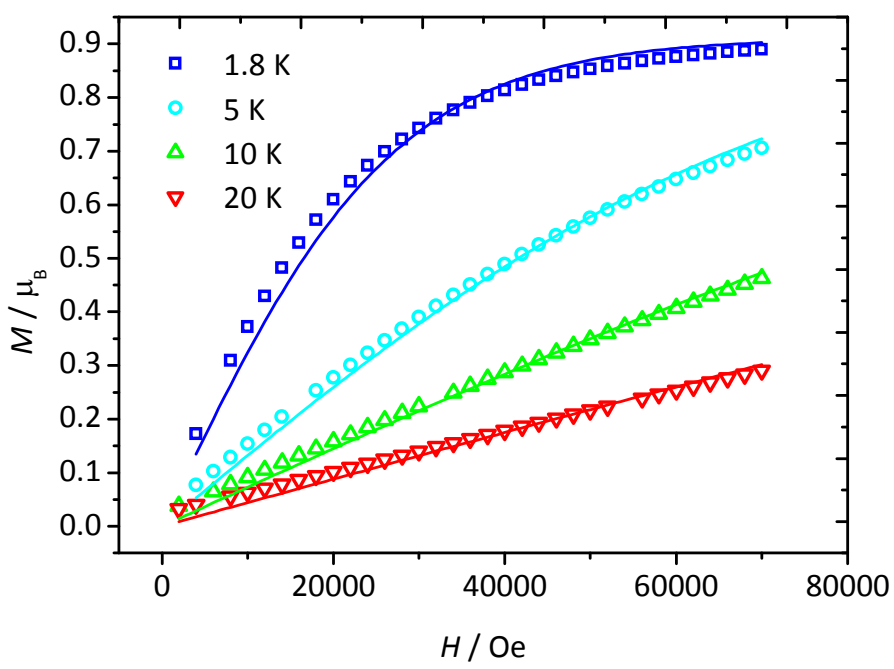

Figure S11: Magnetization as a function of applied magnetic field of $\left[\mathrm{Et}_{3} \mathrm{NH}\right] \mathbf{1 1}$ as Teflon-wrapped powder pellet detected by DC SQUID measurements. Experimental data were corrected for diamagnetism by the means of Pascal's constants (open symbols) and fit with Brillouin functions (solid lines) with fixed $g=2.077$, temperature corresponding to the measurement and $S$ as free parameter $(\approx 1 / 2$ in all cases).

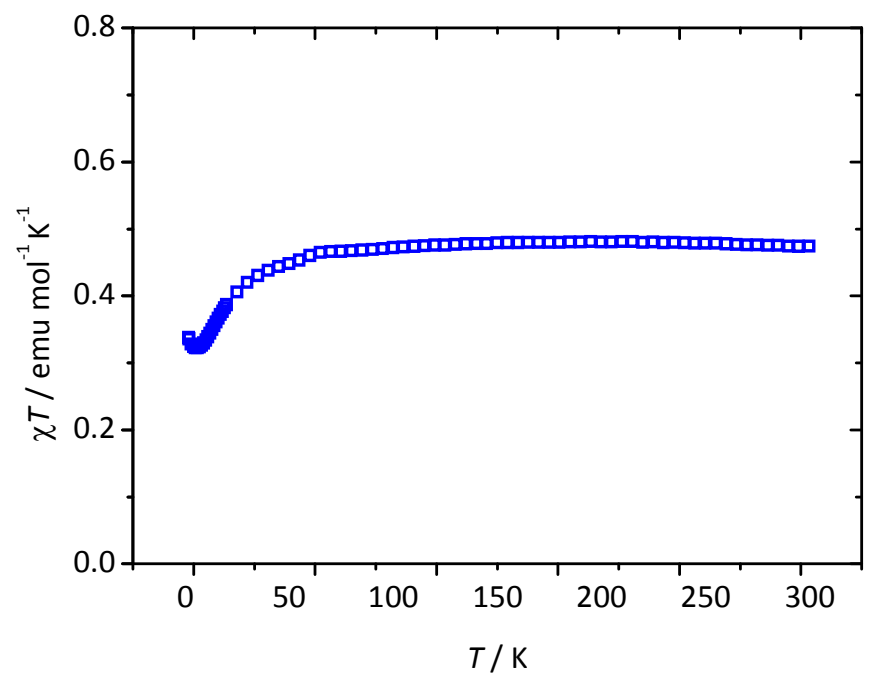

Figure S12: Plot of $\chi \mathrm{T}$ vs. temperature for [ $\left.\mathrm{Et}_{3} \mathrm{NH}\right] \mathbf{1 1}$ as Teflon-wrapped powder pellet detected by DC SQUID measurement. A static magnetic field of 1000 Oe was applied after zero-field cooling of the sample and the experimental data were corrected for diamagnetism by the means of Pascal's constants. 


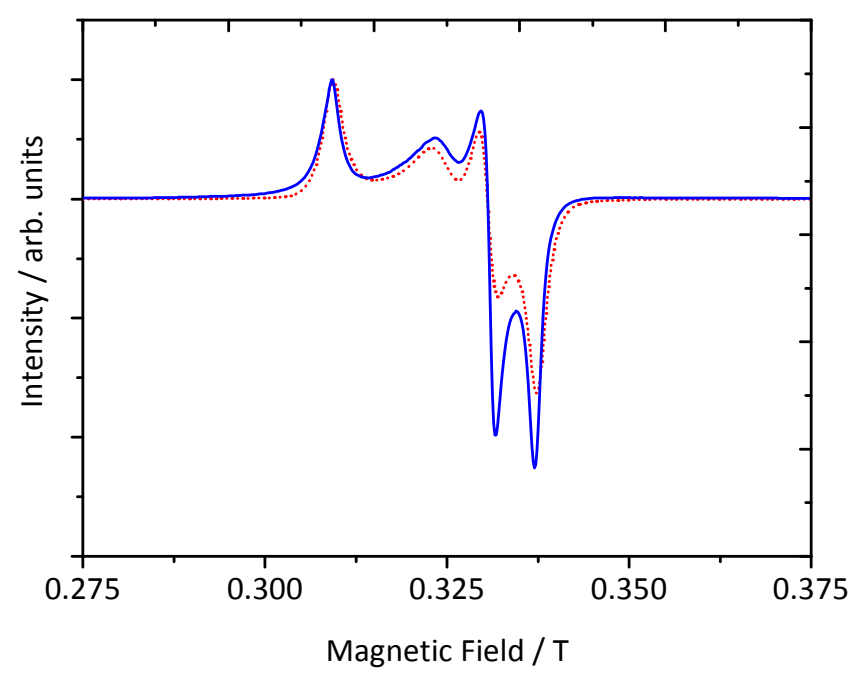

Figure S13: Experimental (blue solid line) and simulated (red dashed line) X-band EPR spectrum of [Et ${ }_{3} \mathrm{NH}$ ]11 (loose powder) at $5 \mathrm{~K}$; simulation parameters: System 1 (weigh 1.0): $g_{\mathrm{x}, 1}=2.005 \pm 0.002, g_{\mathrm{y}, 1}=2.046 \pm 0.002, g_{z, 1}=2.187 \pm 0.002 ;$ system 2 (weight 0.5): $g_{\mathrm{x}, 2}=2.005 \pm 0.002, g_{\mathrm{y}, 2}=2.081 \pm 0.002, g_{\mathrm{z}, 2}=2.187 \pm 0.002$.

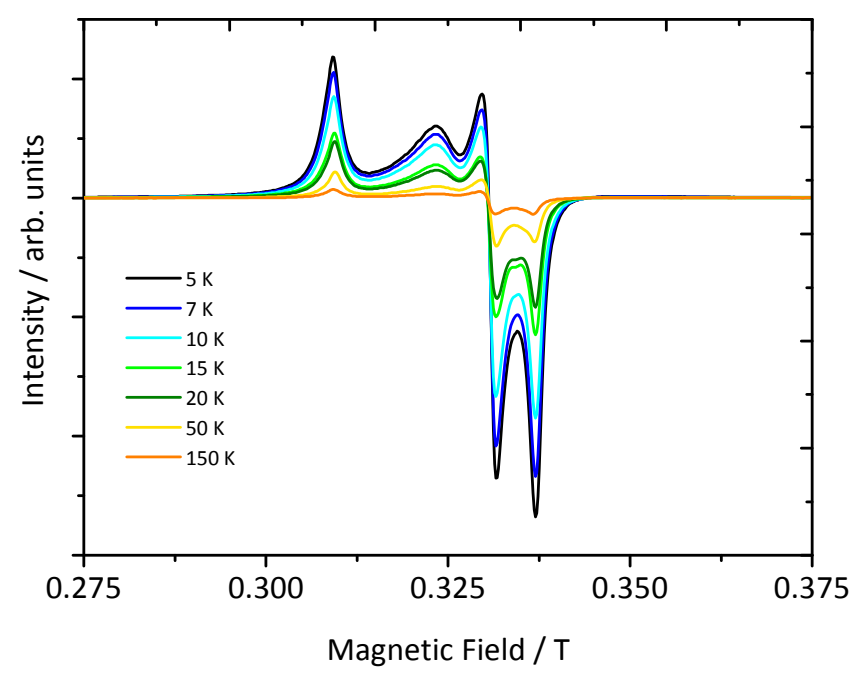

Figure S14: X-band $(9.47 \mathrm{GHz})$ EPR spectra of $\left[\mathrm{Et}_{3} \mathrm{NH}\right] \mathbf{1 1}$ (loose powder) at various temperatures between 5 and $150 \mathrm{~K}$. 


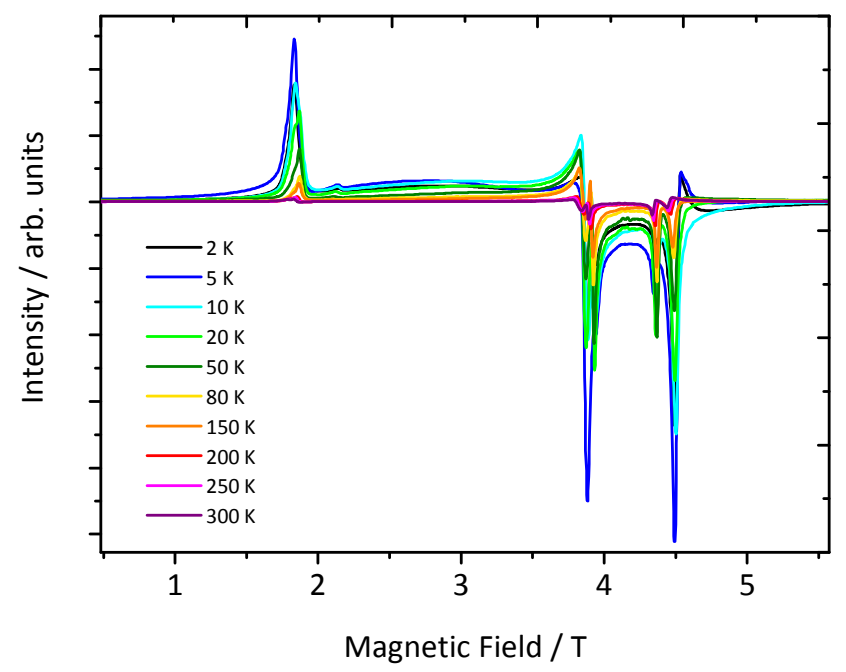

Figure S15: HFEPR $(300 \mathrm{GHz})$ spectra of $\left[\mathrm{Et}_{3} \mathrm{NH}\right] 11$ as pressed powder pellet at various temperatures between 2 and $300 \mathrm{~K}$.
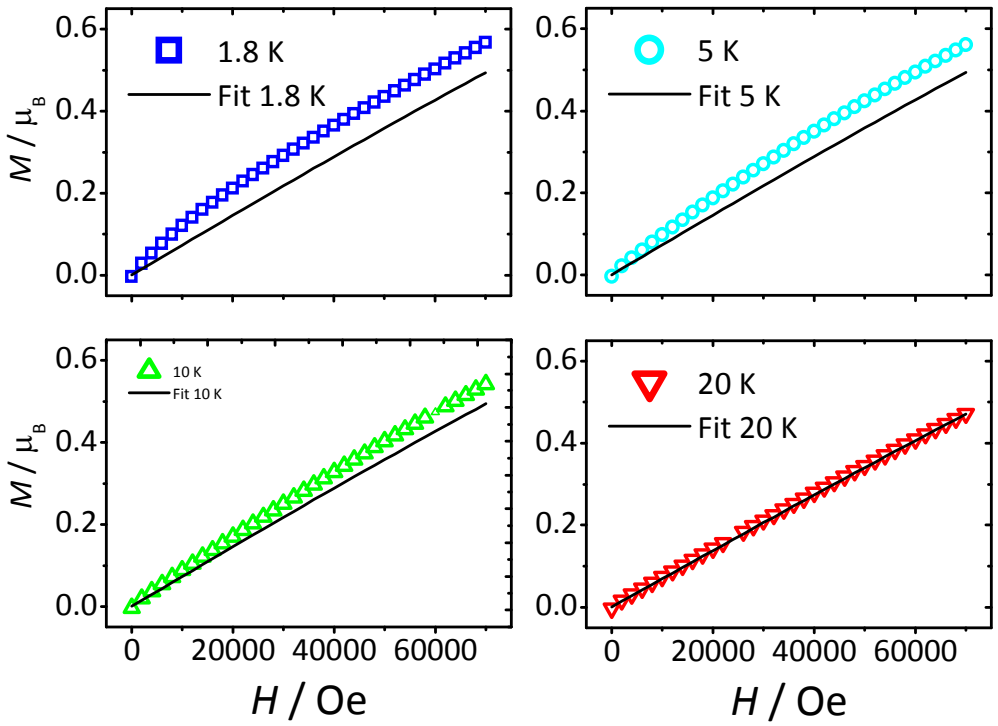

Figure S16: Plot of magnetization vs. applied magnetic field for [NEt 4 ]10 as Teflon-wrapped powder pellet detected by DC SQUID measurement. Experimental data were corrected for diamagnetism by the means of Pascal's constants (open symbols). Simulations (solid lines) were carried out with EasySpin with the following input parameters: $S=1, g=2.27, D=$ $44 \mathrm{~cm}^{-1}$. 


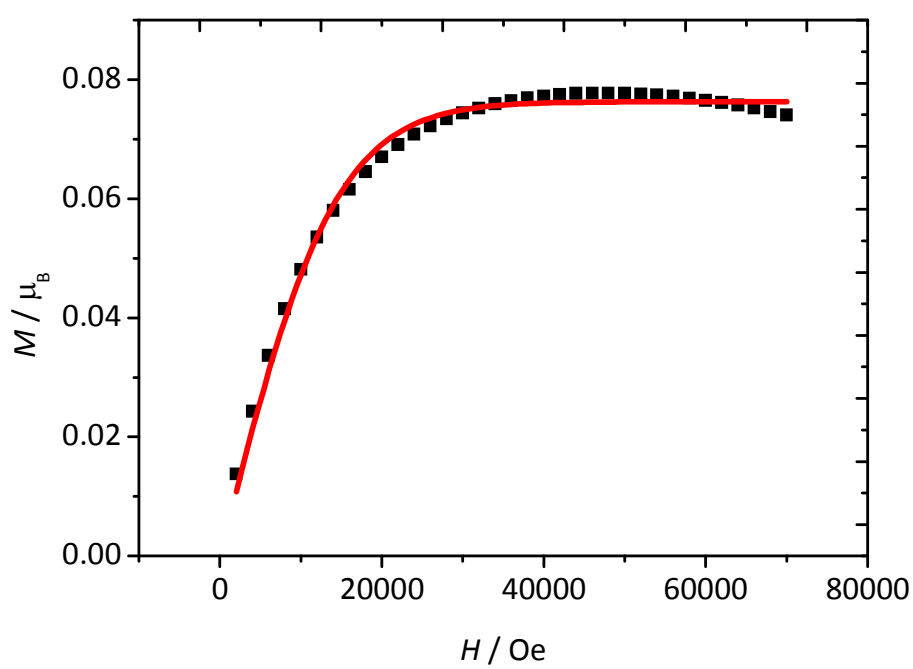

Figure S17: Plot of the difference between measured and simulated magnetization of $\left[\mathrm{NEt}_{4}\right] \mathbf{1 0}$ (black squares) at $T=1.8 \mathrm{~K}$ vs. applied magnetic field. The solid red line was obtained by a fit of the data to a Brillouin fit function with free parameters $g=5.65$ and $S=0.01$. This result indicates that the deviation arises from a paramagnetic impurity.

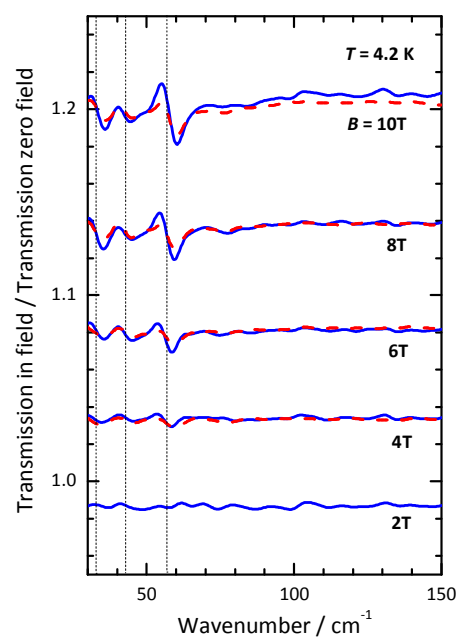

Figure S18: Far infrared spectra of a sample of $\left[\mathrm{NEt}_{4}\right] 10$ diluted with eicosan (1:4, blue solid line and 1:8, red dashed line). Spectra were normalized by the transmission spectrum without applied magnetic field. 


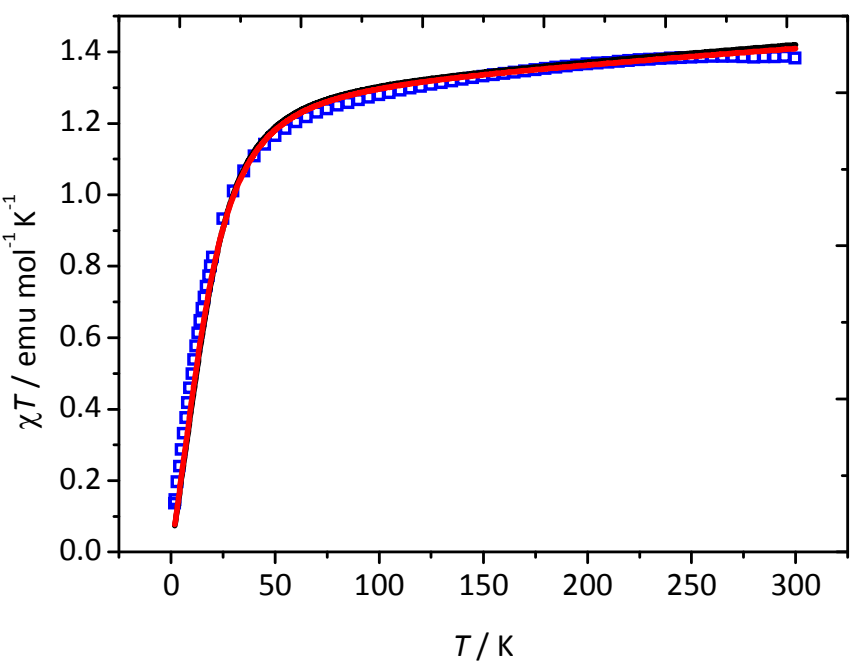

Figure S19: Temperature dependence of $\chi^{\top}$ (open squares) of [NEt $\left.{ }_{4}\right] 7$ as teflon wrapped powder pellet and EasySpin simulations (solid lines, parameters for red line: $S=1, g=2.27, D=33,43,57 \mathrm{~cm}^{-1}$; parameters for black line: $S=1, g=2.27$, $\left.D=44 \mathrm{~cm}^{-1}\right)$. Experimental data were corrected for diamagnetism by the means of Pascal's constants. 